\title{
Academic medicine and the home: work and life in the balance
}

\author{
John W Griffin
}

It is axiomatic that academic medicine has never been so exciting, and that the potential to cure major diseases is within reach. Nevertheless, young faculty members are troubled and uncertain, and their successors - today's traineesoften fear the academic model. Beyond the annual variations in research funding, there is a more persistent source of apprehension, often framed in the students' question, "can I do academic medicine and still have a life?" Many of these individuals observe their mentors' struggles with the work-life balance and decide that the answer is "no".

For most people, 'having a life' means 'having a home life'. In many cases this home life includes children, but, whatever its form, it requires time and effort. Today, a two-income family-often with both partners working in medicine-can be the rule rather than the exception. Older academicians sometimes accuse 'generation X' of lacking a work ethic, without recognizing or acknowledging the extent to which they themselves might have benefited from membership of a two-person work unit in which their partner managed the home.

This issue of work-life balance is admixed with 'women's issues'. Women in many countries are underrepresented at all ranks in the medical academies, and there is a pernicious tendency towards lower pay for women. The argument that discrimination plays a role was vigorously made by Ben Barres in a recent Nature Commentary (Barres BA [2006] Nature 442: 133-136). Nonetheless, for many women the pivotal issue is time. Here is the dilemma: in most current academic systems, time is the coin of the realm and productivity is judged implicitly or explicitly as impact per unit time in rank. The home can make immutable demands on time, however, and child-rearing, family illnesses and other exigencies often arise in the early and vulnerable stages of a career.

My wife, Diane, and I were recently taught the extent to which money can protect time.

The standard
should be
quality of
the research
or other
academic
product,
and this can
be judged
separately
from the rate of
production

We led a session on 'work-life balance' with young academics. In the small sample whom we interviewed, the single-parent families-half of the group-were experiencing greater stress than were the two-parent families. Perhaps surprisingly, however, the difference was not the absence of a supportive partner who did the home and child-care work, but rather the lack of a second income to purchase house-cleaning services, child care and transportation.

To reduce this work-home tension I suggest three fixes to our academic institutions. First, remove the clock from evaluation of an individual. In the early stages of a career, the requirement that an individual must be promotable within a short period can drive out exceptional individuals who have competing time demands. The standard should be quality of the research or other academic product, and this can be judged separately from the rate of production. Johns Hopkins School of Medicine recently eliminated the clock from the promotion process. To prevent abuse by malign Chairs who might be tempted to routinely delay promotion, however, any individual who feels they are ready to be promoted can ask for review at any point. Under such a system, such Chairs would be likely to find themselves in the job market because they would lose their star faculty.

Second, remove any stigma or penalty ensuing from periods of reduced effort. It should be easy and penalty-free to switch to a period of reduced effort with proportionately reduced pay when home needs demand. I have noticed that men are more willing to use this option than are women, perhaps because they trust the system more.

Last, accept the economics of 'having a life': a higher salary early in an individual's career, with smaller increments over time, can protect an individual's time. Today, 'having a life' has a cost, and young academics should not be expected to bear this cost alone. 